\title{
Brexit y la orden de detención europea
}

\author{
Dimitris Liakopoulos ${ }^{1}$ | Fletcher School-Tufts University
}

Revista Derechos en Acción ISSN 2525-1678/ e-ISSN 2525-1686

Año 4/No 12 Invierno 2019 (21 junio a 20 septiembre), 509-530

DOl: https://doi.org/10.24215/25251678e317

ORCID: https://orcid.org/0000-0002-1048-6468

\section{EI Tribunal de Justicia de la Unión Europea tuvo que "reconciliarse" con Brexit: Una premisa explicativa del contexto}

En tiempos recientes, cerca del 29 de marzo de $2019^{2}$, los convulsivos acontecimientos de Brexit y el espectro de una retirada sin acuerdo han polarizado el panorama político en el Reino Unido y Europa. Como saben, inicialmente llegamos a una primera prórroga, el 21 de marzo de $2019^{3}$, y luego a una

\footnotetext{
1 Profesor titular de Derecho de la Unión Europea en la Fletcher School-Tufts University (Master en Derecho Internacional y Master en Derecho y Diplomacia). Profesor titular de Derecho Penal y Procesal Internacional y Europeo en la De Haagse Hogenschool de La Haya. Abogado en Nueva York y Bruselas. El presente trabajo se actualiza hasta mayo de 2019. Email: profd.liakopoulos.984@gmail.com

2 Dado que la notificación por el Reino Unido al Consejo Europeo de la intención de retirarse de la Unión (artículo 50, apartado 2, del TUE) tuvo lugar el 29 de marzo de 2017, el procedimiento debería haber finalizado con la entrada en vigor del acuerdo de retirada 0 , a falta de tal acuerdo, en el plazo de dos años a partir de la notificación, a menos que el Consejo Europeo (de acuerdo con el Estado miembro de que se trate) decida por unanimidad prorrogar dicho plazo (artículo 50, apartado 3, del TUE).

3 Después de que la Cámara de los Comunes rechazara (el 12 de marzo de 2019) el acuerdo de retirada, en la declaración sobre el marco de las futuras relaciones entre la Unión Europea y el Reino Unido se había concedido "una prórroga" hasta el 22 de mayo de 2019, siempre que el acuerdo de desistimiento fuera aprobado la semana siguiente por la Cámara de los Comunes; en caso de no aprobación, el Consejo Europeo había concedido una prórroga hasta el 12 de abril de 2019 en la que pedía al Reino Unido que indicara, antes de esa fecha, el camino que se proponía seguir. El procedimiento de aprobación parlamentaria del acuerdo de retirada está regulado por el artículo 13 de la Ley de (retirada) de la Unión Europea de 2018.
} 
segunda prórroga, el 10 de abril de $2019^{4}$. El último Consejo Europeo extraordinario, que se reunió precisamente el 10 de abril de 2019, concedió una prórroga, con el fin de permitir la ratificación del acuerdo de retirada, que "no debería superar la duración mínima necesaria y en ningún caso el 31 de octubre de 2019”. Sin embargo, si el acuerdo de retirada fue ratificado por las dos partes antes de esa fecha, "la retirada tendrá lugar el primer día del mes siguiente" al término de los procedimientos de ratificación. Esto se refiere a las próximas elecciones europeas. Las conclusiones del Consejo subrayan la necesidad de evitar que la prórroga "comprometa el funcionamiento regular de la Unión y de sus instituciones".

Por lo tanto, "el Reino Unido seguirá siendo miembro de la UE" y si para el 22 de mayo de 2019 no habrá ratificado el acuerdo de retirada tendrá que organizar las elecciones al Parlamento Europeo de acuerdo con la legislación de la Unión”. En caso de que "no cumpla con esta obligación, la retirada tendrá lugar el 1 de junio de 2019”. Además, se reitera que el acuerdo de retirada no puede reabrirse y que cualquier compromiso, declaración u otro acto unilateral debe ser compatible con la letra y el espíritu del acuerdo de retirada y no debe obstaculizar su aplicación. Se especifica, además, que la prórroga no puede utilizarse para iniciar negociaciones sobre futuros informes. Si la posición del Reino Unido cambia, el Consejo Europeo está dispuesto a reconsiderar la declaración política sobre las relaciones futuras de acuerdo con las posiciones y principios

\footnotetext{
4 El 29 de marzo de 2019, la Cámara de los Comunes había rechazado una vez más el acuerdo de retirada; la prórroga concedida por el Consejo Europeo extraordinario del 21 de marzo de 2019 se limitaba automáticamente al 12 de abril de 2019. Para el 10 de abril de 2019 se convocó otro Consejo Europeo extraordinario y la Primera Ministra Theresa May envió el 5 de abril de 2019 al Presidente del Consejo Europeo, Donald Tusk, una carta en la que solicitaba una nueva prórroga, hasta el 30 de junio de 2019, que podría reducirse si el acuerdo de retirada se aprobaba antes de esa fecha. El Consejo Europeo ha acordado esta prórroga para permitir que ambas partes ratifiquen el acuerdo de retirada: como se explica mejor en el texto, la prórroga "no deberá superar la duración mínima necesaria y en ningún caso el 31 de octubre de 2019" (la denominada prórroga).
} 
establecidos en sus directrices y en sus declaraciones, incluido el ámbito territorial de los futuros informes.

La nueva situación hizo necesaria la adopción de la fecha de entrada en vigor del acuerdo de retirada, introduciendo así algunas adaptaciones ${ }^{5}$. Será inevitable volver a los aspectos que acabamos de describir, esbozando, en la fase final, los posibles escenarios de futuro en la materia de nuestro interés.

De hecho, cabe señalar que, en el caleidoscopio polifacético de Brexit, el Tribunal de Justicia de la Unión Europea (TJUE) ya había tenido que "aceptar" el primer caso de retirada de la Unión, interpretando varias veces el arte. 50 TEU (Tribunal de la Unión Europea), que regula esta retirada. Aunque aquí nos referiremos específicamente a la sentencia de los jueces luxemburgueses RO de 19 de septiembre de $2018^{6}$, relativa a las relaciones entre Brexit y la Orden de Detención Europea (EAW), que, entre otras cosas, al ser configurada como la primera en orden cronológico, ha funcionado de alguna manera como un "precursor". Por último, se deben mencionar brevemente otras dos pronunciaciones.

Con la pronunciación en el caso Wightman y otros v. Secretary of State for Exiting the European Union del 10 de diciembre de 2018, el CJEU ha interpretado el art. 50 TUE en el sentido de que, si un Estado miembro ha notificado al Consejo Europeo su intención de retirarse de la Unión, esta disposición permite al Estado en cuestión hasta el plazo de dos años establecido en el artículo Par 503 TUE (finalmente ampliado), para "revocar unilateralmente la notificación, de manera inequívoca e incondicional, mediante comunicación escrita al Consejo Europeo, una vez que el Estado miembro de que se trate haya adoptado

\footnotetext{
5 Véase la Decisión (UE) 2019/642 del Consejo, de 13 de abril de 2019, por la que se modifica la Decisión (UE) 2019/274 en nombre de la Unión Europea y de la Comunidad Europea de la Energía Atómica, del Acuerdo sobre la retirada del Reino Unido de Gran Bretaña e Irlanda del Norte por la Unión Europea y la Comunidad Europea de la Energía Atómica.

6 Conclusiones del Abogado General Maciej Szpuna, publicadas en la Recopilación electrónica de la Jurisprudencia del Tribunal de Justicia.
} 
la decisión de revocación de conformidad con sus disposiciones constitucionales". La revocación tiene por objeto confirmar la pertenencia del Estado "a la UE sin cambios en lo que respecta a su estatuto de Estado miembro y pone fin al procedimiento de retirada" ". En otras palabras, según la Corte de Justicia de la Unión Europea (CJUE), la revocación "refleja la decisión soberana de dicho Estado de mantener el estatuto de Estado miembro de la Unión". La notificación inicial "no tiene por efecto suspenderla o alterarla" (ídem). Más allá de las críticas que se pueden formular sobre algunos pasajes de la sentencia ${ }^{8}$, no se puede negar el valor eminentemente "político", ya que el CJEU ofreció al Reino Unido una vía legal para reconsiderar si realmente pretendía abandonar la Unión.

Pero, como ya sabemos, la ruta elegida fue la de solicitar una prórroga de conformidad con el art. Par 50 art.3 Tribunal de la Unión Europea (TUE), concedido por el Consejo Europeo por primera vez el 21 de marzo de 2019 y por segunda vez el 10 de abril de 2019. Además, parece significativo que tanto en las conclusiones del Consejo Europeo como en la Decisión (UE) 2019/584 adoptada de común acuerdo con el Reino Unido el 11 de abril de 2019, se afirme que éste, de conformidad con el artículo 2, apartado 1, letra a), del Tratado de la Unión Europea, no ha adoptado ninguna medida: "seguirá siendo, durante el período de prórroga, un Estado miembro con todos los derechos

\footnotetext{
7 CJEU, C-621/18, Wightman y otros contra Secretary of State for Exiting the European Union, de 10 de diciembre de 2018.

8 El artículo 3 del TUE prevé la posibilidad de prorrogar el plazo a partir del cual los Tratados no se aplican al Estado miembro de que se trate, decidido por unanimidad por el Consejo Europeo. De acuerdo con el Estado en cuestión se observó lo difícil que resulta comprender por qué este tipo de revocación temporal "debe someterse al consentimiento unánime de los Estados miembros, mientras que una revocación definitiva puede depender de la voluntad exclusiva del Estado que la revoque, con independencia de cualquier otro interés contrario alegado por los demás Estados miembros (...)". Además, el Tribunal de Justicia ha negado la analogía entre la revocación y la solicitud de prórroga, apoyada en cambio por el Consejo y la Comisión, porque sólo en el primer caso el Estado en cuestión tiene la intención de mantener el estatuto de Estado miembro de la Unión. El concepto de confianza mutua entre los Estados miembros también entra en juego.
} 
y obligaciones que de él se derivan, tendrá derecho a revocar su notificación en cualquier momento".

Con la pronunciación M.A. y otros v. Tribunal de Apelaciones de Protección Internacional, Ministro de Justicia e Igualdad, Fiscal General, Irlanda, del 23 de enero de 2019, el CJEU interpretó esto en el sentido de que "la circunstancia de que un Estado miembro, determinado como "competente" en virtud de dicho Reglamento, haya notificado su intención de retirarse de la UE" " ha sido objeto de una solicitud de protección internacional. El art. 50 TUE, "no obliga al Estado miembro que lleva a cabo esta determinación a examinar directamente, en virtud de la cláusula discrecional la citada solicitud de protección". En esencia, la notificación de la intención de un Estado miembro de retirarse de la Unión no cambia su competencia establecida por el Reglamento Dublín III porque la notificación en cuestión "no tiene por efecto suspender la aplicación de la legislación de la UE en ese Estado miembro" y, por lo tanto, "este derecho sigue estando plenamente en vigor" ${ }^{\text {. }}$.

\section{Dudas sobre Brexit y la Orden de Detención Europea (EAW): Las cuestiones preliminares propuestas a los tribunales luxemburgueses en el caso RO (persona con pseudónimo) de 2018}

Centrándonos ahora en la relación entre Brexit y EAW, aquí están los hechos que llevaron al Tribunal Supremo (Alta Corte, Irlanda) a presentar algunas preguntas preliminares a la Corte de Justicia de la Unión Europea. Las autoridades judiciales del Reino Unido habían solicitado la entrega de RO sobre la base de dos órdenes de detención europea al término del ejercicio de una acción penal por los delitos de asesinato, incendio

9 “El sistema de la orden de detención europea: Evolución reciente de la jurisprudencia del Tribunal de Justicia", en Maastricht Journal of European and Comparative Law, 24 (6), 2017, pp. 884ss. T. Opperman, Classen and Nettesheim.

10 Tribunal de Apelaciones de Protección Internacional, Ministro de Justicia e Igualdad, Fiscal General, Irlanda, de 23 de enero de 2019. 
provocado y violación. RO fue detenida en Irlanda el 3 de febrero de 2016 en el marco de la primera orden de detención europea y el 4 de mayo de 2016 en virtud de la segunda, permaneciendo siempre detenida.

La parte interesada se opuso a su entrega al Reino Unido por razones basadas en la retirada de este Estado de la Unión y en el art. 1 de la Convención Europeo de Derechos Humanos (CEDH), afirmando que, si hubiera estado detenido en la prisión de Maghaberry en Irlanda del Norte, podría haber sido sometido a un trato inhumano o degradante; y argumentando que no se sabía cómo se garantizarían los derechos reconocidos por la Decisión marco sobre la orden de detención europea, una vez que el Reino Unido hubiera puesto fin a la Unión. El 16 de abril de 2018 el Tribunal Superior desestimó todos los motivos de oposición presentados por $\mathrm{RO}$, con excepción de la cuestión relativa a las consecuencias de Brexit en relación con el artículo $81 \mathrm{CE} 3 \mathrm{CEDH}^{11}$.

El Tribunal Superior partió de la premisa de que si RO hubiera sido entregada, con toda probabilidad habría permanecido en prisión en el Reino Unido después del 29 de marzo de 2019, es decir, después de la fecha en la que estaba prevista su retirada de la Unión. Obviamente, se predijo que podrían celebrarse acuerdos entre la UE y el Reino Unido para regular sus relaciones en ámbitos como los regulados por la Decisión marco sobre la orden de detención europea, pero, en el momento en que el Tribunal Superior tuvo que tomar una decisión no había claridad al respecto. En particular, no parecía claro si, tras la retirada del Reino Unido, el derecho de un ciudadano de la UE que está sujeto a la jurisdicción del Reino Unido pueda ser juzgado en última instancia por el Tribunal de Justicia de las Comunidades Europeas".

A la luz de lo anterior, el Tribunal Superior propuso cuatro cuestiones preliminares, después de haber examinado en el

11 El Convenio Europeo de Derechos Humanos: A commentary, Oxford University Press, Oxford, 2015. 
local la notificación de la intención del Reino Unido de retirarse de la Unión de conformidad con el artículo 81 del Tratado 50 TEU. La incertidumbre sobre los acuerdos que habrían intervenido para regular las relaciones entre la UE y el Reino Unido tras la retirada de este último y la consiguiente incertidumbre sobre la medida en que el receptor de la orden de detención europea podría, de hecho, disfrutar de los derechos previstos en los Tratados, en la Carta de los Derechos Fundamentales de la Unión Europea (CDFUE) o en la legislación aplicable, en caso de que se entregue al Reino Unido y permanezca en prisión tras la mencionada retirada.

La primera pregunta se refería a si la legislación de la UE exigía que el Estado miembro requerido denegara la entrega al Reino Unido de una persona sujeta a una orden de detención europea (entrega que de otro modo sería exigible en virtud de la legislación nacional de ese Estado miembro), proponiendo una triple alternativa: i) en cualquier caso hacerlo; ii) en algunos casos, teniendo en cuenta las circunstancias específicas del caso; iii) en ningún caso. Con la segunda pregunta, y suponiendo que la respuesta a la primera pregunta fuera sub ii), se preguntó cuáles eran los criterios o consideraciones sobre cuya base el Estado miembro requerido debe decidir si la entrega está prohibida. Con la tercera pregunta, se preguntó si el juez del Estado miembro requerido debería posponer la decisión final sobre la ejecución de la orden de detención europea hasta que se llegara a una mayor claridad sobre el régimen jurídico que se establecerá tras la retirada de la Unión, proponiendo la pequeña triple alternativa antes mencionada.

Por último, en relación con la cuarta cuestión, y suponiendo que la respuesta a la tercera cuestión fuera sub ii), el órgano jurisdiccional remitente preguntó cuáles eran los criterios o consideraciones en los que debía basarse el juez del Estado miembro requerido para decidir si debía aplazarse la decisión final sobre la ejecución de la orden de detención europea. 


\section{La solución aceptada por el CJEU, en consonancia con las conclusiones del Abogado General: Una elección no sólo razonable para llenar un "vacío" temporal de estructura, sino también atenta a la protección de los derechos fundamentales.}

El razonamiento del CJEU se desarrolla de manera lineal, demostrando una plena armonía con las conclusiones del Abogado General (AG). No obstante, cabe señalar que, a partir de ahora, el aspecto más interesante de la pronunciación no reside tanto en la afirmación de principio de que el Derecho de la UE está en vigor en el Estado miembro que ha manifestado la intención de retirarse de la propia Unión hasta su retirada efectiva, y, más bien, en la apreciación específica reservada a los derechos fundamentales del destinatario de la orden de detención europea tras la retirada de la Unión del Estado miembro que haya otorgado el mandato.

Reformulando las cuestiones planteadas, el CJEU sostiene que el órgano jurisdiccional remitente preguntó esencialmente si el artículo 50 TUE debía interpretarse en el sentido de que la notificación por un Estado miembro de su intención de retirarse de la Unión significaba que, en caso de que dicho Estado emitiera una orden de detención europea, el Estado miembro de ejecución debía "negarse a ejecutar "el mandato o "aplazar su ejecución a la espera de que se clarificara el régimen jurídico aplicable en el Estado miembro emisor tras su retirada de la Unión".

Los jueces luxemburgueses comienzan recordando que el principio de confianza mutua entre los Estados miembros impone a cada uno de ellos, "en lo que se refiere al espacio de libertad, seguridad y justicia, la obligación, salvo en circunstancias particulares, de que todos los demás Estados miembros respeten el Derecho de la Unión y, en particular, los derechos fundamentales reconocidos por este último". A continuación, subrayan que el sistema de ejecución que se desprende de la Decisión marco sobre la orden de detención europea se basa 
en el principio de reconocimiento mutuo con la consecuencia de que las autoridades judiciales de la ejecución pueden, por regla general, denegar la ejecución de la orden de detención europea "únicamente por los motivos de no ejecución enumerados exhaustivamente en la Decisión marco" (artículos 3, 4, 4 bis y 5) y subordinar la ejecución exclusivamente a una de las condiciones estrictamente prescritas en la misma. Por lo tanto, mientras que la ejecución de la orden de detención europea "constituye el principio, la denegación de la ejecución se concibe como una excepción y debe estar sujeta a una interpretación restrictiva"12.

Inmediatamente después, sin embargo, el CJEU recuerda haber admitido que "en circunstancias excepcionales" pueden introducirse "limitaciones a los principios de reconocimiento mutuo y confianza entre los Estados miembros", refiriéndose en este sentido a la pronunciación en los asuntos acumulados Aranyosi y Caldararu de 5 de abril de $2016^{13}$, en materia de

12 Corte Justicia Unión Europea (en adelante CJEU) C-327/18, RO, PPU de 19 de septiembre de 2018, op. cit. 37. En el artículo 3 se exponen los motivos de la no ejecución obligatoria de la orden de detención europea. En los artículos 4 y 4 bis se enumeran los motivos de no ejecución facultativos y en el artículo 5 se enumeran los motivos de la no ejecución facultativa.

13 CJEU, C-578/16, C.K. y otros contra Republika Slovenija, de 16 de febrero de 2017. La actitud de los tribunales luxemburgueses en relación con la interpretación del principio de reconocimiento mutuo y confianza mutua en materia de procedimiento civil tiene por objeto alinearse con las "advertencias" formuladas por el Tribunal Europeo en Avotinš. Las razones que subyacen a la interpretación menos rigurosa de este principio en la sentencia antes mencionada no pueden, de hecho, moverse perfectamente en el ámbito del procedimiento civil, teniendo en cuenta la diferencia ontológica de los derechos fundamentales en juego. El CJEU ha ido más allá en el reconocimiento mutuo. En particular, el Abogado General Yves Bot ha declarado que: "En su búsqueda de equilibrio, el Abogado General considera, en primer lugar, que el artículo 1, apartado 3, iría en contra de la redacción de dicho artículo, que, por su lugar y redacción, expresa un motivo de confianza mutua. En segundo lugar, tal noción no estaría de acuerdo con la intención del legislador de la UE de crear un sistema donde sólo en las circunstancias excepcionales descritas en los considerandos (10) y (13) se puede suspender o prohibirse la expulsión de la UE. Por último, un motivo de no reconocimiento en el artículo 1, apartado 3, perjudicaría gravemente la confianza mutua entre las autoridades judiciales en las que se basa la Decisión marco y, en consecuencia, dejaría sin sentido el principio de reconocimiento mutuo (...)". También estamos hablando 
tratos inhumanos o degradantes prohibidos por el arte. 4 de la CFREU $^{14}$.

En estas pronunciaciones el CJEU se ha basado, por un lado, en el arte. 1 par. 3 de la Decisión marco sobre la orden de detención europea, donde "se prevé que esta última no puede implicar la modificación de la obligación de respetar los derechos fundamentales y los principios jurídicos fundamentales" consagrados en los art. 2 y 6 TUE y, por otro, "sobre el carácter absoluto del derecho fundamental garantizado" por el artículo 4 CDFUE.

En el caso en cuestión, en cuanto al problema de los tratos inhumanos o degradantes, el juez remitente, aplicando la prueba de las dos etapas acuñada por el CJEU en Aranyosi y Caldararu, pidió a la autoridad judicial emisora que le informara de las medidas adoptadas para garantizar la protección de los derechos humanos y la información adicional necesaria para evaluar la existencia de un riesgo concreto de que la persona afectada por un mandato en Europa sea sometida a tratamientos similares. Sin embargo, RO afirmó que corría el riesgo de que, debido a la notificación por parte del Reino Unido de su

de otro principio-valor de la Unión, el de la proporcionalidad como equilibrio de intereses y la ampliación de la esfera discrecional del juez interno y de las circunstancias concretas. La cooperación penal no parece ser comparable con un terreno similar y se remonta a la experiencia del mercado único, en términos de protagonismo jurisprudencial decisivo. No olvidemos que la cooperación penal se ha basado en la definición de normas mínimas comunes para delimitar los espacios y los límites de la cooperación entre las autoridades judiciales y policiales en los ámbitos seleccionados por los Estados miembros y por el legislador de la Unión. Por supuesto, podemos hablar de una unificación positiva y normativa durante años en el sector penal y, especialmente después del Tratado de Lisboa, el mérito pertenece al principio de reconocimiento mutuo de las decisiones judiciales, que sigue garantizando una solución media a la integración que se resume en la protección de los derechos fundamentales de los derechos inalienables de las personas y un progreso continuo dictado por los Estados miembros hacia una contribución cada vez más activa y proactiva, un presagio de las innovaciones y los logros con el objetivo principal. En definitiva, el de una integración acelerada y continua pero en el marco de un desarrollo armonioso de todos los intereses de los individuos y no de los Estados.

14 Bernits U. La Carta de los Derechos Fundamentales de la UE cinco años después. La emergencia de un nuevo marco constitucional, Oxford University Press, Oxford, 2015. 
intención de retirarse de la Unión, varios de los derechos reconocidos por la Carta y la Decisión marco dejaran de respetarse una vez que se hubiera producido la retirada.

En este punto, la cuestión se bifurca, teniendo que considerar, por una parte, el período entre la notificación de la intención de retirarse de la Unión y la retirada efectiva; por otra, el período posterior a la fecha en que se produjo la retirada. En el primer aspecto, la respuesta del CJEU es fácil y debe ser compartida $^{15}$. La mera notificación por un Estado miembro de su intención de retirarse de la Unión "no tiene por efecto suspender la aplicación del Derecho de la UE" y, por lo tanto, este derecho, "que incluye las disposiciones de la Decisión marco y los principios de confianza mutua y reconocimiento inherentes a esta última, está plenamente en vigor en dicho Estado hasta su retirada efectiva". Negarse a ejecutar una orden de detención europea en tal caso equivaldría, como sostiene el Abogado General, a "una suspensión unilateral de las disposiciones de la Decisión marco" y estaría en contradicción con su considerando 10, según el cual corresponde exclusivamente al Consejo Europeo "establecer una violación, en el Estado miembro de emisión, de los principios consagrados" por el artículo. 2 TUE a efectos de suspender la aplicación del mecanismo de la orden de detención europea a dicho Estado ${ }^{16}$. En resumen, la mera notificación de acuerdo con el arte. Par 502 TUE por un Estado

\footnotetext{
15 También hay que recordar que, en lo que respecta al recurso por incumplimiento presentado por la Comisión contra Polonia y relativo a la ley de reforma del Tribunal Supremo, entró en vigor el 3 de julio de 2018, en primer lugar, con la orden del Vicepresidente del Consejo de la Unión Europea. En esta se adoptaron medidas provisionales que ordenaban a Polonia que suspendiera de inmediato y con efecto retroactivo la aplicación de las disposiciones relativas a la rebaja de la edad de jubilación de los magistrados de la Corte Suprema de Justicia. Posteriormente, el Tribunal de Justicia (Gran Sala) en espera de la sentencia definitiva, aceptó la solicitud de medidas provisionales presentada por la Comisión. El 3 de abril de 2019, la Comisión Europea inició un procedimiento de infracción, enviando "una carta de emplazamiento a Polonia en relación con el nuevo régimen disciplinario de los jueces".

16 La mencionada "suspensión unilateral" también sería incompatible con el principio general del Derecho de la UE según el cual los Estados miembros no pueden suspender la aplicación de las disposiciones del Derecho de la UE".
} 
miembro "no puede considerarse, como tal, una circunstancia excepcional" ${ }^{\text {"17 }}$ que pueda justificar la negativa a ejecutar una orden de detención europea emitida por el Estado en cuestión.

De este modo, y pasando al segundo perfil, los tribunales luxemburgueses observan que corresponde a la autoridad judicial de ejecución examinar, "tras una evaluación concreta y precisa del caso, si existen razones serias y probadas para creer que, tras la retirada de la Unión del Estado miembro emisor", la persona objeto de la orden de detención europea "corre el riesgo de ser privada de los derechos y libertades fundamentales que se derivan, en esencia, de los artículos 26 a 28 de la Decisión marco" sobre la orden de detención europea, como se afirma en el asunto RO de 2018. En lo que respecta a los derechos fundamentales previstos en el artículo. 4 de la CFREU el Tribunal de Justicia de las Comunidades Europeas tiene un buen criterio, en un primer momento, al declarar que el órgano jurisdiccional remitente podría, sobre la base de la información recibida de la autoridad judicial emisora, "excluir la existencia de un riesgo de que RO se vea sometida, en el Estado miembro emisor, a un trato inhumano o degradante", prohibido por el artículo 81, apartado 1, letra a), del Tratado CE. 4 de la Carta y, por lo tanto, no debe negarse, en principio, a ejecutar una orden de detención europea con este fin, sin perjuicio de la posibilidad, tras su ejecución, de "ejecutar en el ordenamiento jurídico del Estado miembro que haya interpuesto el recurso que le permita impugnar, en su caso, la legalidad de sus condiciones de detención en una institución penitenciaria de dicho Estado miembro". Además, el órgano jurisdiccional remitente podría "cuestionar esta afirmación sobre la base de la constatación de que los derechos de que goza una persona como consecuencia de su entrega en virtud de la Decisión marco ya

\footnotetext{
17 Conclusiones del Abogado General Maciej Szpunar, op. cit. 56. Por otra parte, si “la notificación de la retirada en sí misma se considerase una circunstancia excepcional que socava fatalmente la confianza mutua, ello constituiría un juicio anticipado sobre los motivos de la retirada de un Estado miembro y privaría a la citada disposición de todo efecto útil" (op. cit., apartado 53).
} 
no estarían garantizados tras la retirada de la Unión del Estado miembro expedidor".

A este respecto, el CJEU observa en primer lugar que el Reino Unido forma parte del CEDH y ha incluido en su legislación nacional las disposiciones del artículo. 3, correspondiente al arte. 4 CFREU. Dado que la decisión de retirarse de la Unión no afecta a la obligación del Reino Unido de cumplir con lo dispuesto en el artículo. $3 \mathrm{CEDH}$, no puede justificar una denegación de ejecución de la orden de detención europea motivada por el hecho de que la persona entregada corre el riesgo de sufrir un trato inhumano o degradante. En cuanto a las disposiciones de la Decisión marco, la obligación derivada del artículo 26 (deducción del período de custodia cumplido en el Estado de ejecución) ${ }^{18}$ también se ha incluido en el Derecho interno y se aplica, con independencia del Derecho de la Unión, a toda persona extraditada al Reino Unido, mientras que los artículos 27 (principio de especialidad) y 28 (entrega o extradición posterior $)^{19}$ reflejan los artículos 14 y 15 del Convenio Europeo de Extradición de 1957, ratificado por el Reino Unido, por el que se incorporan estas disposiciones a su Derecho nacional $^{20}$. De ello se deduce que, puesto que los derechos previstos en los artículos 26 a 28 de la Decisión marco sobre la orden de detención europea y los derechos fundamentales

18 CJEU, C-294/16 PPU, JZ de 18 de julio de 2016: publicado en la recopilación electrónica de la jurisprudencia, establece que la noción de "custodia" -entendida como una noción autónoma del Derecho de la UE y, por lo tanto, de interpretación uniforme en todo el territorio europeo- significa una medida no meramente restrictiva, sino privada de libertad que incluye, además de la prisión de custodia, también otras medidas impuestas a la persona interesada que, por su tipo, duración, efectos y modalidades de ejecución, le privan de libertad de forma similar a la privación de libertad.

19 No obstante, como ha señalado el Abogado General, "las disposiciones de la Decisión marco relativas a la situación posterior a la entrega rara vez han sido objeto de una decisión prejudicial por parte de los órganos jurisdiccionales nacionales".

20 CJEU, C-327/18 PPU, RO de 19 de septiembre de 2018, op. cit. 57: concluyendo que los derechos invocados por Rumanía "en estos ámbitos están cubiertos, esencialmente, por la legislación nacional del Estado miembro emisor, independientemente de la retirada de dicho Estado miembro de la Unión". 
establecidos en el artículo. 4 CFREU "protegidas por las disposiciones del Derecho interno en casos no sólo de entrega, sino también de extradición, no están subordinadas a la aplicación de la Decisión marco en el Estado miembro de emisión" y que, previa verificación por el órgano jurisdiccional remitente, "no existen elementos tangibles que demuestren que RO se vea privada del derecho a invocar estos derechos ante los órganos jurisdiccionales de dicho Estado miembro tras la retirada de este último"21.

En conclusión, tal y como afirma el Abogado General, para decidir si se ejecuta una orden de detención europea es necesario que la autoridad judicial de ejecución pueda asumir que respecto de la persona que debe entregarse "el Estado miembro emisor aplicará el contenido sustancial de los derechos derivados del marco de decisión aplicable al período posterior a la entrega", después de la retirada de dicho Estado de la Unión. Presunción de que es admisible si el Derecho nacional del Estado miembro emisor "incorpora el contenido material de esos derechos", en particular porque participa en

21 CJEU, C-327 PPU, RO de 19 de septiembre de 2018, op. cit. 59. A continuación, el TJUE afirma que su análisis no se ve alterado por el hecho de que "es probable que los derechos mencionados no puedan ser objeto de una cuestión prejudicial en ausencia de un acuerdo entre la Unión y el Reino Unido", tras la retirada. Por un lado, de hecho, la persona entregada debe tener la posibilidad de hacer valer los derechos mencionados ante un tribunal del Reino Unido, por otro, "el uso del mecanismo del procedimiento prejudicial ante el Tribunal no siempre ha estado abierto a los jueces llamados a aplicar "la orden de detención europea": hasta el 1 de diciembre de 2014, o cinco años después de la entrada en vigor del Tratado de Lisboa, el Tribunal de Justicia no ha asumido la plena responsabilidad de la interpretación de la Decisión marco, mientras que esta última debía aplicarse en los Estados miembros desde el 1 de enero de 2004. Por lo que se refiere al Reino Unido, artículo 10, apartado 1. § 4 y 5 del Protocolo $n^{0} .36$ sobre las disposiciones transitorias: sobre esta base, el Reino Unido ejerció su derecho de no adhesión y comunicó al Presidente del Consejo que, en relación con los actos de la Unión en el ámbito de la cooperación policial y judicial en materia penal adoptados antes de la entrada en vigor del Tratado de Lisboa, no aceptaba las competencias de las instituciones de la Unión Europea. Sin embargo, posteriormente, el Reino Unido expresó su voluntad de participar en 35 medidas a las que había decidido no adherirse: entre ellas figuraba la Decisión marco sobre la orden de detención europea y, por consiguiente, a partir del 1 de diciembre de 2014, el Tribunal de Justicia es competente para decidir sobre las cuestiones planteadas por el Reino Unido en relación con esta Decisión marco. 
convenios internacionales, como el CEDH y el Convenio Europeo de Extradición de 1957, incluso después de su retirada de la Unión. De ello se deduce que sólo "en presencia de elementos concretos que prueben lo contrario" las autoridades judiciales encargadas de la ejecución pueden negarse a ejecutar la orden de detención europea.

Por otra parte, en la UE, la experiencia ha demostrado que formar parte del CEDH no siempre garantiza un grado suficiente de confianza en el sistema de justicia penal de un Estado miembro. No es casualidad que todas las directivas destinadas a reforzar los derechos y garantías de los sospechosos e inculpados en los procesos penales y de las personas buscadas en los procedimientos de ejecución de la orden de detención europea la hayan recordado en sus considerandos.

Colocando la pronunciación del CJEU en sus coordenadas temporales, se puede apreciar ciertamente porque ha proporcionado una solución razonable -que continuará aplicándose hasta la retirada efectiva del Reino Unido- de un problema estructural, aunque temporal. Otra cuestión es establecer qué escenarios se presentan en el futuro.

\section{Escenarios futuros}

Dentro de la historia que la prensa diaria define comprensiblemente como "caos Brexit", llama nuestra atención la cuestión de los procedimientos de cooperación judicial en materia penal sobre el sistema de la orden de detención europea.

$\mathrm{Al}$ releer las conclusiones del Abogado General en el asunto RO tiene un cierto efecto, con la retrospectiva, la prosa imaginativa de Maciej Szpunar: "No sabemos casi nada de la futura relación jurídica entre la UE y el Reino Unido de Gran Bretaña e Irlanda del Norte". Mirando el procedimiento descrito en el arte. 50 TEU, resumió de la siguiente manera: A falta de "un acuerdo de retirada, en general, y de normas detalladas sobre el procedimiento de entrega o extradición entre la Unión y el 
Reino Unido, en particular, el plazo de dos años sigue siendo de la notificación" (29 de marzo de 2019), mientras que "el resto está escrito en las estrellas".

$\mathrm{Y}$ no parece que las estrellas sean las de la bandera europea" ${ }^{22}$. En sus observaciones finales, por tanto, el Abogado General reiteró: "Brexit es un país desconocido bajo el perfil de la legislación de la UE. Poco se sabe sobre los acuerdos que tendrán que intervenir entre la UE y el Reino Unido después del 29 de marzo de 2019", tanto en general como para el sistema EAW. "Claro, después de la retirada de la Unión, la marea se retirará en un momento dado. La legislación de la UE fluirá a lo largo de los ríos y fuera de los estuarios" ${ }^{23}$.

Otro aspecto digno de mención en las conclusiones en cuestión consistía en subrayar que no había "indicios concretos en el sentido de que las circunstancias políticas que precedieron, dieron lugar o siguieron a la notificación de retirada sean tales que no respeten el contenido sustancial de la Decisión marco y los derechos fundamentales consagrados en la CDFREU" 24 . El Abogado General, para corroborar su declaración, se refirió a la carta de la Primera Ministra Theresa May al Presidente del Consejo Europeo de 29 de marzo de 2017 como parte de la notificación de la intención de retirarse de la Unión, en la que se subrayaba que deseaba "garantizar que Europa siga siendo fuerte y próspera y sea capaz de transmitir sus valores, asumiendo un papel de liderazgo a nivel mundial y protegiéndose contra las amenazas a la seguridad" y que desea que "el Reino Unido, a través de una asociación especial y profunda con la

22 Conclusiones del Abogado General Maciej Szpunar, op. cit. 49 (para la referencia a la existencia, en ese momento, sólo del texto de un proyecto de acuerdo, "publicado por el grupo de trabajo de la Comisión Europea para la preparación y desarrollo o conducción de negociaciones con el Reino Unido "de conformidad con el artículo 50 del TUE").

23 En cuanto a la matriz de la imagen del "río", está tomada del "difunto Lord Denning", quien "declaró en la sentencia HP Bulmer Ltd \& Anor v. J. Bollinger SA \& Ors[1974] EWCA Civ 14, que, "Cuando se trata de asuntos con un elemento europeo, el Tratado es como una marea creciente. Desemboca en los estuarios y sube por los ríos. No se puede contener".

24 Conclusiones del Abogado General Maciej Szpunar, op. cit. 65. 
Unión Europea, desempeñe plenamente su papel con el fin de alcanzar estos objetivos".

De hecho, en el Libro "The future relationship between UK and EU" presentado por el Primer Ministro británico al Parlamento en julio de 2018 afirmó que el Reino Unido, con fines de prevención y protección de la seguridad, aspiraba a mantener su participación en algunos instrumentos, que "evitan que los delincuentes utilicen las fronteras internacionales para evitar la detección y la justicia, protegen contra las amenazas a la seguridad pública y protegen a los ciudadanos y a las víctimas de delitos".

Se atribuyó una indudable relevancia, en la medida en que es de interés en este caso, al sistema de la orden de detención europea, dado que "la rápida extradición de individuos para asegurar que sean enjuiciados o cumplan penas de prisión es una herramienta vital para impartir justicia y ayudar a mantener seguras a las comunidades". Se reconoció que la orden de detención europea "ha simplificado el proceso de extradición para que sirva como sentencia para una condena existente". En el libro mencionado se recordaba que en el Reino Unido, desde abril de 2009, más de doce mil personas habían sido detenidas y que, por cada persona detenida a raíz de una orden de detención europea emitida por el Reino Unido, ocho personas habían sido detenidas en el Reino Unido sobre la base de una orden de detención emitida por otros Estados miembros. Por lo tanto, habiendo establecido que los tratados de extradición estipulados con terceros países no alcanzaban niveles de eficiencia equivalentes a los de la orden de detención europea, el Reino Unido mostró interés en alcanzar un acuerdo con la UE que permitiera volver a utilizar el mecanismo después de la retirada, de los procedimientos de entrega con implicaciones paradójicas en cierto modo en la era posterior a la de Brexit, bien consideradas en la doctrina.

Además, el Acuerdo sobre la retirada del Reino Unido e Irlanda del Norte de la UE y de la Comunidad Europea, aprobado por el Consejo Europeo el 25 de noviembre de 2018, 
ahora adaptado tras la prórroga concedida al Reino Unido el 11 de abril de 2019 y reeditado, se basa en otras posiciones. Considerando que el Acuerdo, de tener éxito, se beneficiaría de un período de transición que comenzaría desde la fecha de entrada en vigor hasta el 31 de diciembre de 2020 y que durante este período la legislación de la UE se aplicaría al Reino Unido, a menos que se acuerde otra cosa. También se afirma que la Decisión marco sobre la orden de detención europea "se aplica a las órdenes de detención europeas si la persona buscada fue detenida antes del final del período transitorio con el fin de ejecutar una orden de detención europea, que la autoridad judicial de la ejecución decide mantener detenida o poner en libertad a la persona buscada". Pero, según el art. apartado 3 del Acuerdo, se establece que, en el momento de la notificación escrita de la conclusión de los procedimientos internos necesarios, la Unión podrá declarar excepciones inherentes a los principios fundamentales de su Derecho nacional, que durante el período transitorio las autoridades judiciales de la ejecución de dicho Estado miembro podrán negarse a entregar a sus ciudadanos al Reino Unido que esté en vigor una orden de detención europea ".

En este caso, el Reino Unido "podrá declarar, en el plazo de un mes a partir de la recepción de la declaración de la Unión, que sus autoridades judiciales competentes pueden negarse a entregar a sus propios ciudadanos a ese Estado miembro". Además, en una carta se establece que la Decisión marco 2009/829/JAI se aplica "a las decisiones sobre medidas cautelares recibidas antes del final del período transitorio por la autoridad central o la autoridad competente del Estado de ejecución, o por una autoridad del Estado de ejecución que no sea competente para reconocer la resolución pero que la transmita automáticamente a la autoridad competente para su ejecución" ${ }^{\prime 25}$.

25 Decisión marco 2009/829/JAl del Consejo, de 23 de octubre de 2009, relativa a la aplicación, entre Estados miembros de la Unión Europea, del principio de reconocimiento mutuo 
En la Declaración Política que define el marco de las futuras relaciones entre la UE y el Reino Unido, en el punto 84 se afirma que las futuras relaciones "deberían incluir acuerdos en tres áreas de cooperación:

a) Intercambio de datos;

b) cooperación operativa entre las autoridades policiales y

c) cooperación judicial en materia penal; lucha contra el blanqueo de capitales y la financiación del terrorismo”.

Centrándose en la segunda de estas áreas, las partes "reconocen la importancia de facilitar la cooperación operativa entre las autoridades judiciales y policiales del Reino Unido y de los Estados miembros y, por lo tanto, trabajarán conjuntamente para definir los términos de la cooperación del Reino Unido a través de Europol y Eurojust"; y, a continuación, formulan observaciones que las partes "deberían establecer acuerdos efectivos basados en procedimientos y términos racionalizados que permitan al Reino Unido y a los Estados miembros entregar a los sospechosos y a los condenados de forma rápida y eficaz, con la posibilidad de derogar el requisito de la doble incriminación, y determinar la aplicabilidad de tales acuerdos a sus propios ciudadanos y en caso de delitos políticos" 26 .

Sin embargo, hay que recordar que en el ámbito europeo nos preparábamos para cualquier eventualidad, por lo tanto también en la recesión del Reino Unido sin acuerdo, un espectro que se ha cernido sobre Brexit en los últimos acontecimientos. En un documento de la Comisión la cooperación judicial en materia penal también fue obviamente abordada y, en la medida en que se refería específicamente a la orden de detención europea se predijo el posible retorno a la disciplina en materia de extradición.

\footnotetext{
a las resoluciones sobre medidas de vigilancia como sustitución de la prisión provisional.

26 Decisión marco 2009/829/JAI del Consejo, de 23 de octubre de 2009, relativa a la aplicación, entre Estados miembros de la Unión Europea, del principio de reconocimiento mutuo a las resoluciones sobre medidas de vigilancia como sustitución de la prisión provisional.
} 
Si tras la última prórroga solicitada por el Reino Unido y las determinaciones ya mencionadas del Consejo Europeo extraordinario de 10 de abril de 2019, se ratificara el acuerdo de retirada, se preveía la posibilidad de un acuerdo especial entre la Unión Europea y el Reino Unido, de conformidad con el acuerdo entre la UE y la República de Islandia y el Reino de Noruega $^{27}$ relativo al procedimiento de entrega entre los Estados miembros de la UE, Islandia y Noruega.

El acuerdo, que entrará en vigor "el primer día del tercer mes siguiente a la fecha en que el Secretario General del Consejo de la UE compruebe el cumplimiento de todas las formalidades requeridas para la expresión del consentimiento de las partes del acuerdo". Aunque se inspira en las normas resultantes del texto original de la Decisión marco sobre la orden de detención europea, todavía contiene referencias residuales a perfiles típicos de la disciplina de extradición.

En cuanto al delito político, la norma según la cual la ejecución no puede denegarse por el hecho de que el Estado de ejecución pueda considerar que el delito es un delito político sólo puede aplicarse en relación con determinados delitos atribuibles a la matriz terrorista. Del mismo modo, la entrega de los ciudadanos sólo puede denegarse o autorizarse en determinadas condiciones y se mantiene la participación de la autoridad política. Sin embargo, el acuerdo presenta algunos aspectos de interés, como la constante actualización de la evolución de la jurisprudencia del Tribunal de Justicia de las Comunidades Europeas y

\footnotetext{
27 Véase, por ejemplo, Brexit: Futuro de la seguridad y cooperación policial entre la UE y el Reino Unido. En los puntos 129 a 133 se examinó el acuerdo celebrado entre la Unión Europea y la República de Islandia y el Reino de Noruega como alternativa a la orden de detención europea con lo que se pusieron de manifiesto los aspectos positivos y negativos; sin embargo, en el punto 141 se concluyó que: “la vía más prometedora que puede seguir el Gobierno puede ser la de seguir el precedente establecido por Noruega e Islandia y buscar un acuerdo bilateral de extradición con la UE que refleje en la medida de lo posible las disposiciones de la orden de detención europea", al tiempo que lamenta que el acuerdo en cuestión, firmado diez años antes, aún no haya entrado en vigor, porque: "una laguna operativa entre el cese de la aplicación de la orden de detención europea y la adecuada entrada en vigor de una nueva orden de detención europea supondría un riesgo inaceptable".
} 
de los tribunales islandeses y noruegos competentes en relación con las disposiciones del acuerdo, así como la revisión común del acuerdo en un plazo de cinco años a partir de su entrada en vigor. Por el contrario, la solución de las controversias relativas a la aplicación o interpretación del propio acuerdo es de carácter intergubernamental y no judicial (art. 36 del acuerdo) ${ }^{28}$.

Si no se siguiera el procedimiento de acuerdo específico, una vez que el Reino Unido se convirtiera en un tercer Estado, no quedaría más remedio que volver a la disciplina de la extradición, regida por el Convenio del Consejo de Europa de 1957, ratificado por todos los Estados miembros de la UE, y de la que el Reino Unido seguiría siendo parte. Esta elección constituiría sin duda un "revés" con respecto al mecanismo de la orden de detención europea, aunque el CJEU también ha dado pasos innovadores importantes en este frente. En el caso Petruhhin, de hecho, los tribunales luxemburgueses han resuelto dos cuestiones que prohíben toda discriminación basada en la nacionalidad y prevén el derecho de todo ciudadano de la Unión a circular y residir libremente en el territorio de los Estados miembros. Si una solicitud de extradición es presentada por un tercer Estado con el que el primer Estado miembro ha celebrado un acuerdo de extradición, este último deberá informar al Estado miembro del que sea nacional la persona de que se trate y, si fuera necesario, a petición de este último Estado miembro, entregarle a dicho ciudadano con arreglo a lo dispuesto en la Decisión marco sobre la orden de detención europea. En el caso concreto, el Sr. Petruhhin, ciudadano estonio, había sido detenido en Letonia y el Fiscal General de la Federación de Rusia había presentado una solicitud de extradición contra él, con la que la UE no tiene ningún acuerdo de extradición.

En opinión del CJEU, a falta de disposiciones legales de la UE que regulen la extradición entre los Estados miembros y un

\footnotetext{
28 En efecto, el litigio "podrá ser sometido por una de las partes a los representantes de los Gobiernos de los Estados miembros de la Unión Europea y de Islandia y Noruega reunidos a efectos de su composición en un plazo de seis meses".
} 
tercer Estado, es necesario aplicar todos los mecanismos existentes de cooperación y asistencia mutua en materia penal en virtud del Derecho de la UE con el fin de proteger a los ciudadanos europeos contra las medidas que puedan privarlos de la libre circulación y de los derechos de residencia, "luchando al mismo tiempo contra la impunidad de los delitos". El Estado miembro de acogida no está obligado a conceder al ciudadano de otro Estado miembro la misma protección contra la extradición concedida a sus propios ciudadanos en su territorio, sino que, cooperando con el Estado miembro del que es ciudadano, el interesado "actúa de manera menos perjudicial para el ejercicio del derecho a la libre circulación, evitando al mismo tiempo, en la medida de lo posible, el riesgo de que el delito perseguido permanezca impune".

Además, al resolver otra cuestión preliminar, el CJUE ha declarado que si un Estado miembro recibe una solicitud de un tercer Estado para la extradición de un ciudadano de otro Estado miembro el primero debe verificar que la extradición no menoscaba los derechos a los que se refiere el artículo 19 de la Carta de los Derechos Fundamentales de la Unión, en virtud de la cual nadie puede ser extraditado.

En conclusión, el Reino Unido, transformado en un tercer Estado debería garantizar los derechos fundamentales para garantizar que sus solicitudes de extradición dirigidas a un Estado miembro de la UE sean aceptadas; una protección similar a la establecida en la CDFUE, tal y como la interpreta la CJUE.

Pero, por las razones ya señaladas, la mejor manera de avanzar es celebrar un acuerdo entre el Reino Unido y la $\mathrm{UE}^{29}$, en el que se transfieran, en la medida de lo posible, las disposiciones de la Decisión marco sobre el mandato del euro.

\footnotetext{
29 V. MITSILEGAS, ¿el derecho penal europeo sin el Reino Unido? La triple paradoja de brexit, op. cit., "Ios acuerdos UE-Reino Unido sobre diversos aspectos de la cooperación en materia de justicia penal" son "los más deseables en términos de garantizar la seguridad jurídica, el establecimiento de una igualdad de condiciones a escala de la UE para el Reino Unido, y la eficiencia operativa en la medida en que tienen el potencial de mantener la posición del Reino Unido lo más cerca posible de su posición actual como Estado miembro de la UE".
} 